\title{
Woelfel's Dental Anatomy
}

\section{Rickne C Scheid, Gabriela Weiss}

Publisher: Lippincott Williams \& Wilkins

Language: English

ISSN: 978-1-60831-746-2

Edition: 8/e

Publish Year: 2012

Pages: 520, illustrated

Price: $\$ 86.99$

A very important book on dental anatomy at its 8th edition, Woelefel's Dental Anatomy written by Rickne C. Scheid and Gabriela Weiss, is a study guide for dental students, dental hygiene students, dental assistants, and dental laboratory technicians.

The book is divided into three parts:

The first Part, Comparative Tooth Anatomy, has six chapters: an introduction to terminology and concepts related to tooth morphology, and the description of: incisors, canines, premolars, and molars; the last chapter is foccussed on primary and mixed dentition.

Second part, Application of Tooth Anatomy in Dental Practice, with seven chapters, begins with the adult teeth roots related to periodontal procedures; then endodontic procedures are described, followed by an overview of functional occlusion and malocclusion; operative and restorative dentistry, dental anomalies, and forensic dentistry. The last chapter is a guideline for drawing, sketching, and carving the teeth, intended as a help for students.

The third part, Anatomical Structures of the Oral Cavity, presents in two chapters the

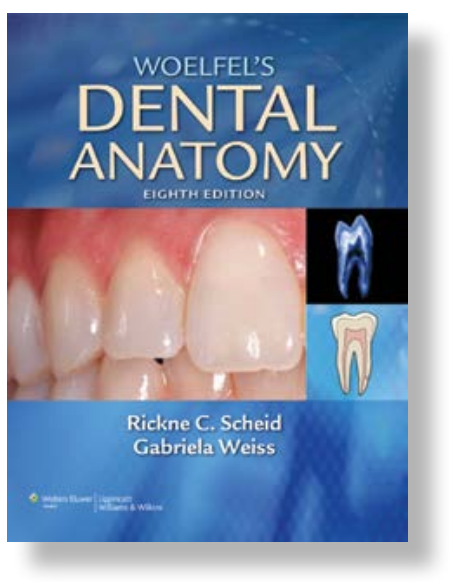

relationship of the teeth to landmarks of the skull, temporomandibular joints, and the muscles, nerves, vessels, associated with the oral cavity, as well as the visible structures on a panoramic radiography; and also the intra- and extra-oral examination of normal oral structures.

This dental anatomy book links anatomy to clinical practice enabling a practical understanding of tooth structure and function, the dental morphology and terminology and hence the application of the professional knowledge to patient evaluation, treatment and education. The book was republished, revised and updated and has clear explanations, colored illustrations and hands-on exercises.

To facilitate the study and application of dental anatomy, the book also offers special chapters on practical aspects, such as: learning objectives, new terms, review questions and answers, learning exercises and an appendix.

The book is also useful to dental anatomy courses instructor, as a teaching manual during lectures, discussion periods, and laboratory sessions, as well as during early clinical experiences. It is also useful as a reference in the dental office.

\section{Marian-Vladimir}

Constantinescu

https://doi.org/10.25241/stomaeduj.2015.2(1).bookreview.4

partment of Prosthetic Dentistr

"Carol Davila" University

of Medicine and Pharmacy

Bucharest, Romania

The Book Review is drafted in the reviwer's sole wording and illustrates his opinions. 